1 Universidade Federal da Fronteira Sul (UFFS) Chapecó (SC), Brasil. daniela.geremia@uffs.edu.br

2 Fundação Oswaldo Cruz (Fiocruz), Escola Nacional de Saúde Pública Sergio Arouca (Ensp) - Rio de Janeiro (RJ), Brasil.

\section{0 anos de SUS: relação público-privada e os impasses para o direito universal à saúde}

\author{
30 years of the SUS: public-private relationship and the impasses for \\ the universal right to health
}

lanka Cristina Celuppi', Daniela Savi Geremia', Jéssica Ferreira', Adelyne Maria Mendes Pereira², Jeane Barros de Souza'

DOI: 10.1590/0103-1104201912101

RESUMO Este estudo analisou a relação público-privada nos 30 anos do Sistema Único de Saúde (SUS), bem como os impasses que repercutem na efetivação do direito universal à saúde. A pesquisa totalizou a participação de 12 atores do Movimento da Reforma Sanitária Brasileira (MRSB), que foram entrevistados no período de janeiro a março de 2018. Utilizou-se um roteiro de entrevista com questões semiestruturadas, pelo formulário on-line do Google (Google Forms). As entrevistas foram analisadas pelo método do discurso do sujeito coletivo, resultando em quatro ideias centrais: 1) Neoliberalismo e organização capitalista do sistema de saúde; 2) A relação público-privada na construção do SUS; 3) Estratégias de privatização e o financiamento do SUS; 4) Conjuntura e perspectivas em defesa do SUS. Como resultado da pesquisa, pode-se perceber a disputa de poderes nas esferas política, social e econômica na relação público-privada no sistema de saúde brasileiro. As conjecturas postas contribuíram para o subfinanciamento da saúde e consequente fortalecimento do mercado privado, que atua de forma paralela e competitiva ao SUS. Assim, a defesa da saúde como direito passa pela radicalização de bandeiras do MRSB, como as reformas política, tributária e agrária, bem como a renovação da luta social em defesa do SUS.

PALAVRAS-CHAVE Setor privado. Direito à saúde. Privatização.

\begin{abstract}
This study analyzes the public-private relationship in the 30 years of the Unified Health System (SUS), as well as the impasses that impact on the accomplishment of the universal right to health. The research relied on the participation of twelve actors of the Brazilian Sanitary Reform Movement (MRSB), who were interviewed in the period from January to March, 2018. An interview script with semistructured questions was used, using the Google online form. The interviews were analyzed by the discourse method of the collective subject, resulting in four central ideas:1) Neoliberalism and the capitalist organization of the health system;2) The public-private relationship in the construction of the SUS; 3) Strategies for the privatization and financing of the SUS; 4) Conjuncture and perspectives in defense of the SUS. As a result of the research, one can perceive the disputes for power in the political, social, and economic spheres in the publicprivate relationship in the Brazilian health system. The conjectures set forth contributed to the
\end{abstract}


underfunding of health and the consequent strengthening of the private market, which operates in a parallel and competitive way to the SUS. Thus, health defense as a universal right requires the radicalization of MRSB agendas, such as political, tax, and agrarian reforms, as well as the renewal of the social struggle in defense of the SUS.

KEYWORDS Private Sector. Right to health. Privatization.

\section{Introdução}

Ao celebrar os 30 anos de instituição do Sistema Único de Saúde (SUS), comemora-se também as transformações em saúde que decorreram da implementação do sistema de saúde no País em termos de inclusão social, universalização e integralização da assistência. Cabe destacar que o ideal de saúde pública como direito foi concebido em meados da década de 1970 com o Movimento da Reforma Sanitária Brasileira (MRSB), em um momento histórico no qual os cidadãos se uniram em prol da redemocratização do Estado e construção de políticas públicas populares.

Esse processo democrático foi marcado pela cooperação entre movimentos sociais, movimentos estudantis, sindicatos e organizações trabalhistas, que inspiraram a criação de instituições suprapartidárias centradas na equidade e na universalidade do acesso à saúde, a exemplo do Centro Brasileiro de Estudos de Saúde (Cebes) em 1976 e da Associação Brasileira de Pós-Graduação em Saúde Coletiva (Abrasco) em 1979.

A concepção do MRSB transcendeu às políticas estatais, configurando-se como um projeto de reforma social que direcionou suas indagações para a redução das desigualdades e justiça social, por meio de transformações sanitárias nas dimensões institucional, ideológica e das relações sociais $\mathbf{1}$. Desse modo, o MRSB extrapola o conceito de uma reforma setorial, trata-se de uma reestruturação do Estado, que carece de articulação com as reformas tributária, política e agrária.
No ano de 1986, a VIII Conferência Nacional de Saúde (CNS) - que apresentava o lema: saúde é democracia - definiu o conceito ampliado de saúde como um direito universal de todo e qualquer cidadão, independentemente de vínculo empregatício como vinha ocorrendo até o momento com o Instituto Nacional de Assistência Médica da Previdência Social (Inamps). Nessa ocasião, desenhou-se o que posteriormente seriam as bases para a construção do SUS, instituído na Constituição Federal de 1988 (CF/1988).

Trata-se de um sistema desafiador, tanto na sua organização quanto no seu financiamento, especialmente ao instituir o acesso universal, equitativo, descentralizado, com gestão dos governos subnacionais, além de dividir seu espaço com o setor privado de saúde, amparado constitucionalmente como suplementar ${ }^{2}$.

A assistência à saúde suplementar no Brasil é composta por 1.125 operadoras, grande parte presta serviços médico-hospitalares, cobrindo $25,2 \%$ da população brasileira ${ }^{3}$. A dinâmica da assistência privada é parasitária à lógica estatal, pois, contribui para a mercantilização da saúde, oferta ações e serviços médico-curativos individualizados e visa ao lucro com a assistência, o que resulta em um sistema nacional de saúde paralelo e duplicado.

O subfinanciamento do SUS e a convivência com um setor privado robusto e competitivo são decorrentes de múltiplos fatores, contudo, destacam-se algumas hipóteses. A primeira delas é a manutenção da simbiose público-privado existente desde o período Inamps, configurada pela implantação de 
equipamentos e serviços públicos, preservando o investimento privado já existente. Outra hipótese refere-se ao baixo engajamento e compromisso de partidos políticos com a construção de um sistema de saúde universal no Brasil, que negociam suas candidaturas diretamente com o mercado privado de saúde. Ademais, também se ressalta a construção do ideal de que 'o privado é melhor do que o público', sob sagaz influência da grande mídia brasileira, que resulta no maior desejo da sociedade pela assistência privada 4 .

A partir desse contexto, surgiram alguns questionamentos: de que modo os ideais do SUS estão sendo implementados no decorrer de seus 30 anos? Como pode-se manter a estabilidade e a sustentabilidade do financiamento público do SUS neste cenário de incentivos ao mercado privado de saúde? Quais as principais estratégias para o fortalecimento da luta em defesa da saúde pública?

Nessa perspectiva, tem-se como objetivo analisar a relação público-privada nos 30 anos de construção do SUS a partir das percepções de atores-chave do MRSB. Ao resgatar o processo histórico de implementação do setor saúde no Brasil, espera-se contribuir para a análise dos diversos condicionantes da privatização da saúde, bem como suas repercussões sobre a efetivação do direito universal à saúde.

\section{Metodologia}

Trata-se de um estudo analítico, de abordagem qualitativa, que integra o projeto de pesquisa intitulado 'Privatização da saúde: impasses políticos e sociais observados por atores do movimento da reforma sanitária brasileira', aprovado no edital no 398/2017/UFFS, institucionalizado na Universidade Federal da Fronteira Sul (UFFS) e deferido pelo Comitê de Ética em Pesquisa da UFFS pelo parecer $\mathrm{n}^{\mathrm{o}} 2.448 .574$.

A pesquisa teve como público-alvo pesquisadores e militantes da saúde pública que participaram do MRSB vinculados ao Cebes e/ ou à Abrasco, e que ainda apresentavam vinculação a essas entidades. As informações para a seleção dos participantes foram coletadas por meio da análise de produções científicas, bem como pela atuação nas entidades supracitadas. A partir dos critérios estabelecidos, a pesquisa envolveu 12 participantes.

A média de idade dos participantes foi de 65 anos; em que a menor idade foi de 58 anos, e a maior, de 71 anos. Destes, nove apresentaram titulação de doutorado; e três, de pós-doutorado. O tempo de militância pela saúde pública informado no formulário expressa uma longa jornada em defesa do SUS, em que 83,3\% afirmaram militância de mais de 30 anos; e os demais, um período de 21 a 30 anos.

A coleta de dados foi realizada por meio de um formulário semiestruturado, contendo oito perguntas abertas, organizadas em três eixos: I - Ideais do MRSB; II - Percepções acerca do processo de privatização da saúde pública no Brasil; III - Projeções e expectativas para o futuro do SUS. A coleta de dados foi realizada mediante envio de um formulário eletrônico do Google (Google Forms), durante os meses de janeiro a março de 2018.

Os dados foram analisados pelo método do Discurso do Sujeito Coletivo (DSC). Tratase de um método qualitativo que permite a sistematização e a análise do material empírico a fim de expressar o pensamento de uma população sobre um determinado tema. Entre as etapas do método, estão: 1) análise minuciosa das entrevistas para identificação das Expressões-Chave (EC) presentes no texto. Essas EC consistem em trechos das entrevistas que revelam a essência do conteúdo abordado; 2) após a sinalização das EC, une-se o conjunto de expressões semelhantes, criando as Ideias Centrais (IC), que descrevem sucintamente o sentido de um composto de falas. 3) A partir das IC, constroem-se os DSC sobre a temática em questão $0^{5,6}$.

A partir da análise dos resultados, emergiram quatro ideias centrais: 1) Neoliberalismo e organização do sistema de saúde; 2) A relação público-privada na construção do SUS; 3) 
Estratégias de privatização e o financiamento do SUS; 4) Conjuntura e perspectivas em defesa do SUS.

\section{Resultados e discussões}

\section{Neoliberalismo e organização do sistema de saúde}

O neoliberalismo está ancorado em pretensões de desmonte dos sistemas de proteção social e incentivos à autorregulação dos mercados. No Brasil, essas diretrizes configuram-se como estratégias que vão ao encontro de um continuum processo de americanização do sistema de saúde brasileiro. À sombra das políticas econômicas estadunidenses e das influências do Banco Mundial, principalmente nos países em desenvolvimento, o movimento de contrarreforma do Estado brasileiro avançou na estruturação de políticas sociais residuais, sob o desígnio de limitá-las ao mero assistencialismo ${ }^{7}$.

Os interesses do Banco Mundial na mercantilização do setor saúde no Brasil foram acentuados com a criação do SUS. O sistema de saúde público e universal foi entendido como um novo espaço a ser explorado pelo mercado. À vista disso, as políticas públicas brasileiras foram orientadas por documentos lançados pelo Banco Mundial, que apresentavam o intuito de reduzir os serviços públicos à população pobre e ofertar um mercado robusto para as classes de renda média e alta ${ }^{8}$.

A concepção de Estado autônomo leva ao discurso de 'crise do Estado', que justifica a ineficiência estatal devido à adoção de exacerbadas funções sociais, originando investimentos com políticas sociais que extrapolam os cofres públicos. Ao contrário, a relação entre Estado e poder econômico aponta que a crise da saúde pública brasileira não resulta apenas da 'ineficiência do Estado', mas configura-se como produto estrutural do sistema de produção capitalista9 .
A conjuntura de expansão do mercado privado e enfraquecimento das políticas sociais é congruente com o modelo econômico brasileiro e operacional aos interesses das organizações privadas no País, conforme aponta o DSC 1.

DSC 1: O MRSB e o SUS culminaram em um projeto político de inspiração socialista. Frente ao enfraquecimento dessa perspectiva político-ideológica e à evolução do capitalismo e da ideologia neoliberal nos últimos 30 anos, o crescimento do mercado privado no setor saúde e a profunda dilapidação do Estado, são coerentes e funcionais ao modelo econômico brasileiro.

Em síntese, as recomendações do Banco Mundial apresentavam os objetivos de reorientar os gastos públicos em direção à Atenção Primária à Saúde (sob o intuito de focalizar as ações e serviços nas populações vulneráveis), avançar na descentralização do sistema de saúde; conter custos (por meio do direcionamento dos investimentos para procedimentos de alto custo efetividade); criar um ambiente regulatório que possibilitasse a livre atuação do setor privado; cobrar o pagamento de usuários de renda média e alta pelo uso do sistema público e limitar a atuação do governo federal às funções de assistência técnica, pesquisa e regulação dos serviços privados ${ }^{10-12}$.

Os 30 anos de instituição do SUS foram permeados pelas políticas de governos neoliberais, nas quais criaram-se incentivos fiscais ao setor privado, atacaram-se os direitos trabalhistas, houve limitação da expansão do sistema público, adotaram-se políticas financeiras de austeridade e limitaram-se os investimentos públicos na saúde, conforme apresenta o DSC 2.

DSC 2: O mercado privado já existia antes do SUS, e aproveitou-se da sua fragilidade, especialmente no que refere-se ao subfinanciamento crônico e à sabotagem das áreas econômicas e políticas dos governos de corte neoliberal que não priorizaram a sua expansão no pós-88. 
Apesar de toda luta dos movimentos sociais e da instituição do direito à saúde na $\mathrm{CF} / 88$ como direito humano fundamental, durante governos de esquerda, não foi possível romper com a ideologia neoliberal e apoiar as bases teóricas socialistas que estruturaram o sistema universal de saúde. É válido destacar que esses governos obtiveram avanços nas políticas públicas de saúde e na defesa dos direitos sociais, reduzindo a desigualdade social e econômica no País. Os resultados são inegáveis. Entretanto, durante o seu exercício do poder, não foi resgatado em sua essência o ideal de justiça social dos movimentos socialistas, caracterizando-os como governos de centro-esquerda.

No período do governo Luiz Inácio Lula da Silva, o Brasil distanciou-se do receituário neoliberal e passou a reduzir simultaneamente a pobreza e a desigualdade de renda ${ }^{7}$. Contudo, ainda aponta-se para um conjunto de estratégias a serem empregadas no combate à desigual repartição de renda e inclusão social. Apesar de todo esforço das iniciativas políticas do período Lula, faltaram reformas essenciais em seu governo para impactar diretamente na saúde, tais como: reforma fiscal, política e agrária, também bandeiras do MRSB, como observa os DSC 3 e 4.

DSC 3: O esforço que foi feito em algumas áreas do sistema público de saúde durante o Governo Lula (2003-2011), especialmente a expansão da Atenção Básica através do Programa de Saúde da Família (PSF), bem como a formulação de algumas políticas como a de promoção da Saúde e outras, não foram suficientes para reverter uma tendência que se fortaleceu no governo Dilma e assume uma dimensão enorme no atual Governo Temer.

DSC 4: Esta conjuntura reducionista de direitos sociais também é resultante da ausência de um projeto de desenvolvimento nacional autônomo e progressista, da derrota do projeto socialista idealizado no MRSB, da perda das capacidades de liderança política e da dificuldade na formulação e construção de uma coalizão dos partidos de esquerda que sustente o SUS.
Em meio à organização de políticas públicas e às estruturas privatizantes do Estado projetadas pelo neoliberalismo, percebe-se um espaço de inexatidão entre o público-coletivo e o privado-mercado, que insere as políticas sociais em um cenário de hostilidade.

\section{A relação público-privada na cria- ção do SUS}

A VIII CNS é considerada um marco histórico na construção do SUS, pois sediou ostensivos debates populares que resultaram nos pilares que o sustentaram dois anos depois. A conferência apresentou três eixos norteadores: I - Saúde como direito, II - Reformulação do Sistema Nacional de Saúde; e III Financiamento do setor. O relatório final da VIII CNS é um documento memorável, pois responsabiliza o Estado pela organização de políticas públicas, defende a garantia do acesso universal à saúde e afirma a necessidade de efetivar a reforma sanitária brasileira por meio da vinculação com as políticas econômica e social do País.

As diretrizes almejadas durante o MRSB eram, contudo, incompatíveis com o modelo de saúde do período anterior à $\mathrm{CF} / 88$, em que o Estado alicerçava a sua focalizada assistência à saúde nos investimentos e serviços privados já existentes. Os DSC 5 e 6 apresentam alguns reveses no que tange à mudança do modelo de saúde e aos ajustes na relação público-privada no setor.

DSC 5: Durante a VIII Conferência Nacional de Saúde havia uma polêmica que distinguia setores do movimento sanitário, onde um segmento vinculado ao Partido dos Trabalhadores (PT) defendia a 'Estatização' do sistema de saúde, e outro mais moderado, imaginava a possibilidade de desencadear um processo gradual de fortalecimento do setor público, de modo a tornar o setor privado residual, tendo como imagem-objetivo o National Health Service (NHS) inglês. O MRSB apresentava o projeto de fortalecimento do setor público de saúde, visando a expansão dos recursos financeiros, da rede de serviços e 
consequente aumento de cobertura, tendo em vista o alcance da universalidade e integralidade da atenção à saúde.

DSC 6: O SUS foi concebido como um sistema único, de natureza pública, universal, democrático, integral e de responsabilidade do Estado. O setor privado residual seria uma concessão pública e estaria subordinado ao controle estatal, tanto no sentido de disciplinar sua existência e tamanho, bem como os seus modos de funcionamento.

Como apresentado no DSC 5, o National Health Service (NHS) da Inglaterra é reconhecido como um dos sistemas de saúde estatais mais eficientes e acessíveis do mundo. O NHS foi implementado na Inglaterra no cenário de restabelecimento socioeconômico pós-segunda guerra mundial, sendo parte de um conjunto de iniciativas que construíram o Welfare State no País. Por esse motivo, é percebido como um referencial precursor dos sistemas universais de saúde, figurando o necessário limite à influência do mercado para a garantia da universalidade da saúde ${ }^{\mathbf{1 3}}$.

Pesquisadores apontam que a reforma social-democrata brasileira não se deu nos moldes do Welfare State dos países europeus, que mesmo mantendo o modelo capitalista, adotaram características e políticas redistributivas. O sistema de proteção social brasileiro conciliou focalização e universalização, em vez de reforçar esta última. Assim, a efetivação de uma reforma semelhante à dos países europeus demandaria a busca por um Welfare State construído nas contradições do capitalismo, pelo fortalecimento de serviços públicos e da capacidade da sociedade, com enfoque na ampliação do controle do setor privado pelo Estado e sociedade, limitando as ações do mercado ${ }^{\mathbf{1 4}}$.

\section{Estratégias de privatização e o financiamento do SUS}

Por vezes, ignoram-se as causas histórico-estruturais que influenciam no pleno funcionamento do SUS, dentre as quais, podem-se destacar: a hegemonia do modelo assistencial biologicista centrado no profissional médico; o modelo e estrutura de governo adotado no País, que carrega heranças do forte período de centralização de poder; os incentivos à iniciativa privada na saúde, inclusive sob a forma de renúncias fiscais; o encorajamento pelos sindicatos dos trabalhadores para que as empresas garantam aos funcionários planos privados de saúde; estímulo financeiro governamental para que os servidores públicos façam adesão aos planos privados; a aprovação da Emenda Constitucional 95 (EC nº 95/2016), que propõe o congelamento de gastos em serviços primários; a abertura do capital estrangeiro para explorar o setor de assistência à saúde; a ampliação dos modelos alternativos de gestão; aprovação da lei dos planos populares e a depreciação do SUS encampada pelas grandes mídias.

As organizações privadas de saúde estão articuladas com os mais variados setores da sociedade e detêm o poder de influenciar diretamente nas políticas econômica e social do País. Tendo em vista a hostilidade do cenário político-econômico brasileiro, percebe-se que são inúmeras as propostas de redução do sistema de saúde e expansão do mercado privado no Brasil.

A mais recente articulação do poderio econômico do setor saúde corresponde à criação da Federação Brasileira de Planos de Saúde (Febraplan) em 2018, considerada nova entidade representativa dos planos e seguros privados. Os empresários do setor reuniram-se com instituições governamentais e profissionais do legislativo brasileiro para elaborar uma nova proposta de sistema nacional de saúde ${ }^{15}$. Somado a isso, a grande mídia nacional desempenha função primordial no que se refere a manipulação popular, imposição ideológica e destruição das políticas públicas sociais, principalmente o SUS. Tal afirmação pode ser evidenciada nos DSC 7 e 8. 
DSC 7: A defesa da privatização não é mais feita apenas pelos atores políticos diretamente beneficiados por este processo, mas também por políticos cujas campanhas foram financiadas por empresas privadas de saúde. O nosso atual Ministro [referente ao gestor de 2017] apregoa que o SUS é inviável e propõe a criação dos 'planos populares de saúde', em um contexto onde o congresso conservador aprovou a EC 95/2016, que congela os gastos públicos por 20 anos, o que significa uma 'pá de cal' no processo de construção do SUS.

DSC 8: Outro agravante é o apoio massivo da grande mídia institucionalizada, que reproduzem cotidianamente um discurso contrário à expansão do SUS e sub-repticiamente estimulam o hiperconsumismo promovido pelo setor privado de assistência à saúde.

A aprovação da EC 95/2016 resulta no congelamento dos gastos em serviços primários por tempo estimado de 20 anos. Essa medida consiste na retração do financiamento do sistema de saúde brasileiro, que se torna um agravante ainda maior para a sustentabilidade e manutenção do SUS. A perda significativa de recursos proposta por essa medida obriga os gestores e secretários a reduzirem as ações e serviços disponíveis aos usuários, sob o preceito de diminuir as despesas dos estados e municípios.

O SUS é instituído com financiamento tripartite e deve ser responsabilidade das três esferas federativas. Entretanto, em seus 30 anos, não foram definidas as suas fontes de financiamento nem os critérios de alocação dos recursos públicos, o que comprometeu a sustentabilidade de recursos para o desenvolvimento e expansão do sistema de saúde, que sempre disputou recursos com a previdência e assistência social dentro do Orçamento da Seguridade Social ${ }^{16}$.

A EC 29/2000 (atual Lei n ${ }^{\circ} 141 / 2012$ ) não foi capaz de garantir a solidariedade entre municípios, estado e governo federal. Ao invés disso, acirrou as disputas por ampliação da arrecadação tributária municipal, uma vez que o percentual de aplicação definido se dá sobre a base de arrecadação. Nessa lógica, aplicar altos percentuais em cima de uma base fraca não significa absolutamente nada no que diz respeito ao aumento considerável de recursos. Nesse ínterim, houve um maior agravamento da situação dos municípios, que são, em sua maioria, de pequeno porte e não conseguem arcar financeiramente com suas atribuições, que cada vez são maiores ${ }^{17}$.

Nesse contexto, em relação ao precário financiamento público da saúde, somando-se à aprovação da Lei de Responsabilidade Fiscal (LRF) que limita o percentual de gasto com pessoal, as alternativas propostas indicam como solução para a baixa efetividade do sistema público entregá-lo para as empresas privadas por meio da terceirização da gestão pública. Desde o Plano da Reforma do Estado no governo Fernando Henrique Cardoso, a gestão da saúde tornou-se outro campo de aproveitamento para o capital na saúde ${ }^{\mathbf{1 8}}$. As modalidades alternativas de gestão visam transferir para o setor público não estatal os serviços do Estado, que é o principal responsável pelo planejamento e execução das políticas sociais. Ademais, também contribuem para o fortalecimento do mercado privado e caracterizam-se como uma forma passiva de privatização do SUS, como apresenta os DSC 9 e 10.

DSC 9: O crescimento do mercado privado é resultante de estímulos dos governos de corte neoliberal, que em termos do financiamento e da gestão do sistema de saúde, sempre buscaram favorecer a expansão do setor privado, seja na produção de serviços ou na inserção deste setor na gestão pública.

DSC 10: A lei de responsabilidade fiscal levou os gestores a buscar novas formas de administrar suas unidades, privatizando a gestão através das Organizações Sociais de Saúde (OSS). Embora as OSS's não sejam organizações tipicamente privadas, terminam participando no fortalecimento de agentes de mercado por meio de contratos com fornecedores, por exemplo empresas e grupos empresariais de diagnóstico. 
São muitos os impactos resultantes da terceirização da gestão pública: desresponsabilização do Estado de suas obrigações, precarização das condições de trabalho, diminuição de salários, desestabilização dos direitos trabalhistas e priorização da lógica quantitativista de produção na assistência à saúde. Outrossim, as OSS também ferem as características constitucionais do SUS, no momento em que desempenham gestão centralizadora e normativa, distante dos fóruns de participação popular e controle social.

Com o intuito de dinamizar os investimentos privados para o crescimento do mercado, durante o governo Dilma Rousseff, foi aprovada a Lei $n^{0} 13.097 / 2015$ que permite a participação direta ou indireta de empresas ou capital estrangeiro na assistência à saúde. Essa lei permitiu a instalação, operacionalização ou exploração de hospitais gerais, clínicas especializadas e clínicas gerais pelo capital internacional. A tendência é que se crie um setor oligopolizado, aos moldes do modelo estadunidense, de modo a ampliar o poder de negociação e influência dos grandes grupos internacionais.

A iniciativa apresenta o objetivo de difundir o mercado de planos de saúde, considerando o panorama de recessão econômica, diminuição da renda média e aumento do índice de desemprego. A flexibilização das normativas que regem o subsistema privado, somado à abertura do investimento de capital estrangeiro na saúde, faz parte de um engenhoso movimento em prol da internacionalização da economia no País.

\section{Conjuntura e perspectivas em de- fesa do SUS}

Atendendo ao exposto até o momento, cabe refletir sobre a sustentabilidade política, institucional e econômica do SUS, no intuito de conceber alternativas que permitam não retroceder na universalização do direito à saúde. O panorama apresentado a seguir assume dimensão oposta à efetivação do sistema de saúde idealizado pelo MRSB e proposto na Constituição: público, universal e de qualidade.

Assim, o quadro 1 apresentado a seguir expõe alguns dos aspectos que foram idealizados pelo MRSB na construção do sistema de saúde e que são determinantes para a garantia do acesso e expansão dos serviços públicos, bem como a maneira como foram organizados no decorrer da implementação do SUS e como repercutem atualmente nos seus 30 anos.

Quadro 1. Impasses para a efetivação do direito universal à saúde

\begin{tabular}{|c|c|c|}
\hline Categoria & Ideais do MRSB & Conjuntura dos 30 anos do SUS \\
\hline $\begin{array}{l}\text { Criação do } \\
\text { SUS }\end{array}$ & $\begin{array}{l}\text { Implantação do Estado democrático de direito; } \\
\text { Saúde como direito de cidadania para além da reforma } \\
\text { setorial; } \\
\text { Defesa das reformas agrária, política e tributária; } \\
\text { Estatização progressiva dos serviços de saúde; } \\
\text { Fortalecimento dos serviços públicos. }\end{array}$ & $\begin{array}{l}\text { Manutenção e fortalecimento do mercado privado; } \\
\text { Enfraquecimento dos serviços públicos. }\end{array}$ \\
\hline $\begin{array}{l}\text { Relação pú- } \\
\text { blico-privada } \\
\text { e sustentabi- } \\
\text { lidade política } \\
\text { no período } \\
\text { pós-1988 }\end{array}$ & $\begin{array}{l}\text { Atuação complementar do setor privado sob forte } \\
\text { regulação do Estado; } \\
\text { Expansão progressiva dos serviços de saúde, alcançan- } \\
\text { do os princípios da universalidade do acesso, equidade, } \\
\text { integralidade da assistência, participação da comunida- } \\
\text { de, descentralização político-administrativa, regionali- } \\
\text { zação e hierarquização dos serviços. }\end{array}$ & $\begin{array}{l}\text { Subsistema que compete diretamente com o SUS; } \\
\text { Flexibilização da Lei no 9.656/98 que regulamenta os planos de saúde e } \\
\text { consequente criação dos 'planos populares de saúde'; } \\
\text { Inserção do mercado privado na gestão dos serviços públicos por meio da } \\
\text { terceirização da gestão; } \\
\text { Abertura do investimento de capital estrangeiro na assistência à saúde; } \\
\text { Desmoralização política e rompimento da democracia;. }\end{array}$ \\
\hline
\end{tabular}




\begin{tabular}{|c|c|c|}
\hline & & $\begin{array}{l}\text { Sabotagem político-econômica de alguns governos que sucederam a cria- } \\
\text { ção do SUS; } \\
\text { Adoção de políticas econômicas que favoreceram a expansão do mercado } \\
\text { privado; } \\
\text { Aplicação das diretrizes propostas pelo Banco Mundial }\end{array}$ \\
\hline $\begin{array}{l}\text { Financiamento } \\
\text { do SUS }\end{array}$ & $\begin{array}{l}\text { Definição de fontes de arrecadação específicas para o } \\
\text { setor saúde; } \\
\text { Destinação de percentual do PIB semelhante ao de } \\
\text { países que também apresentam sistema universal de } \\
\text { saúde. }\end{array}$ & $\begin{array}{l}\text { Indefinição de fontes e critérios de alocação de recursos; } \\
\text { Repartição do Orçamento da Seguridade Social (OSS) entre previdência, } \\
\text { saúde e assistência social, sendo que as duas últimas sempre foram preju- } \\
\text { dicadas; } \\
\text { Desvinculação das Receitas da União (DRU); } \\
\text { Aprovação da EC 95/2016 que congela os gastos em serviços primários } \\
\text { por } 20 \text { anos; } \\
\text { Mudanças nas formas de transferências financeiras entre os fundos de } \\
\text { saúde. }\end{array}$ \\
\hline $\begin{array}{l}\text { Participação e } \\
\text { controle social }\end{array}$ & $\begin{array}{l}\text { Arranjos institucionais e processos de deliberação } \\
\text { por meio de instâncias de negociação e pactuação na } \\
\text { formulação e na implementação da política de saúde; } \\
\text { Mobilização e politização da opinião pública em defesa } \\
\text { do SUS. }\end{array}$ & $\begin{array}{l}\text { Baixo nível de compreensão dos conselheiros de saúde sobre o SUS; } \\
\text { Pouca participação e controle social; } \\
\text { Desmobilização e despolitização social da opinião pública em defesa do } \\
\text { SUS. }\end{array}$ \\
\hline
\end{tabular}

Os dilemas que anteriormente eram avaliados como dificuldades a serem enfrentadas para o predomínio do sistema público estatal, hoje são considerados produto de uma consistente estruturação da política de Estado neoliberalista do Brasil ${ }^{19}$. Assim, o primeiro desafio está no enfrentamento do projeto hegemônico neoliberal resultante da supremacia de forças políticas retrógradas e conservadoras, que propõem o desmonte das políticas públicas sociais no País. Dessa forma,

[...] estes avanços permanecem muito mais condicionados à relação de forças sociais, econômicas e políticas, no que toca ao grau de consciência dos direitos sociais e mobilização social $^{19}$ [conforme apresenta os DSC 11 e 12].

DSC 11: Precisamos fortalecer as bases do movimento sanitário, ampliando o debate entre estudantes, profissionais de saúde e de outros setores, buscando articulação com movimentos sociais de resistência, além de ocupar espaços na mídia alternativa, usando as redes sociais para desconstruir o discurso hegemônico. Ou seja, devemos manter-se em movimento, atentos à dinâmica política da conjuntura, tratando de estabelecer diálogos construtivos com outras forças sociais empenhadas em resistir a esta onda conservadora, criando espaços para a revisão e 'aggiornamento' das propostas do MRSB no momento atual.

DSC 12: O Brasil passa claramente por mais um momento de recrudescimento da luta de classes. O fortalecimento do MRSB e do SUS passa diretamente pela politização deste processo, com a população e os movimentos sociais indo à rua, exigindo o cumprimento da máxima constitucional que apresenta a saúde como um direito de todos e um dever do Estado. O caminho é a luta, nas suas mais diferentes formas de ação.

Por conseguinte, torna-se fundamental estreitar as relações entre as entidades da sociedade civil e os movimentos sociais, principalmente com os trabalhadores sindicalizados, que, há algum tempo, abandonaram a defesa do SUS e hoje contribuem para a expansão do mercado privado e concentram suas forças na conquista de cobertura dos planos de saúde.

Convém retomar o protagonismo da crítica 
e da práxis nos debates, com o propósito de avançar para além do que já está posto. A vitalidade do MRSB está relacionada com a constituição de sujeitos 'portadores da antítese'20, que podem auxiliar na efetivação dos ideais e das propostas do movimento por meio da prática. A formação desses sujeitos supõe um sujeito social que possa contribuir no sentido de fazer avançar o processo da reforma sanitária brasileira para além do status quo ou da revolução passiva que marca a história do Brasil1,20, o que se observa no DSC 13.

DSC 13: Devemos mobilizar a população por democracia e contribuir para formação de sujeitos 'portadores da antítese', que contribuam para o adensamento conceitual e construção de novas bases para o diálogo teórico-empírico na reflexão crítica. E devemos resistir. Renovar a luta e os atores sociais. Politizar o campo da saúde coletiva. Participar dos poderes, eleger representantes comprometidos com a reforma sanitária que é bem mais ampla que o SUS, mas envolve um modelo de estado com democracia social, direitos e justiça.

O MRSB não atingiu o objetivo de uma reforma geral, entretanto, contribuiu para a ampliação do conceito de saúde e para a estruturação do sistema de seguridade social no País, caracterizando-se como uma reforma de caráter parcial. O diálogo e a contraposição de conceitos advindos dos sujeitos da antítese apresentam potencial transformador para impulsionar o MRSB para uma reforma de caráter geral, mediante uma práxis criadora, reflexiva e política ${ }^{20}$.

\section{Conclusões}

Este artigo resgatou elementos históricos que influenciaram na estruturação dos ideais do MRSB ao longo de 30 anos de advento do SUS e de 42 anos de criação do Cebes. Pode-se identificar a descontinuação do projeto social almejado e concretizado na $\mathrm{CF} / 88 \mathrm{Na}$ atualidade, o SUS tem sofrido um processo sistemático e intencional de fragmentação e desfinanciamento. A luta de caráter reformista tão forte e presente na década de 1970 tem sido golpeada pela desmobilização e despolitização da sociedade em defesa da saúde pública, que, cada vez mais, tem sido reduzida pelos governos a uma política assistencialista.

Entretanto, vale destacar que o SUS constitucional precisa ser fortalecido. Esse sistema é considerado referência para os outros países, uma vez que ampliou a cobertura de assistência à saúde para toda a população brasileira, ofertando serviços de atenção primária, secundária e terciária. Nesses 30 anos de SUS, puderam-se instituir a Estratégia Saúde da Família (ESF), as Unidades de Pronto Atendimento (UPA), as vigilâncias em saúde, o tratamento para HIV/Aids, os tratamentos oncológicos, os transplantes de órgãos e tecidos, o Serviço de Atendimento Móvel de Urgência (Samu), os serviços de atenção psicossocial e saúde mental, a coleta e transfusão de hemoderivados, entre outros avanços.

Conforme apontou esta pesquisa, a relação público-privada no sistema de saúde brasileiro é caracterizada pela disputa de poderes entre as esferas política, social e econômica. O SUS, desde a sua criação, foi prejudicado na expansão de serviços, na definição de fontes de recursos e na concessão de subsídios financeiros da União, resultando em um cenário de subfinanciamento crônico da saúde pública, que impera como um dos maiores impasses para a gestão e efetivação do direito universal à saúde como direito de cidadania. Essa situação é propícia para a priorização, expansão e fortalecimento do mercado privado de saúde, impactando profundamente no SUS. Nesse sentido, sugere-se o aumento dos investimentos da União e dos estados, definição de novas fontes de recursos, a exemplo da destinação de recursos do pré-sal para a saúde e educação.

O mercado suplementar de saúde, na análise empreendida pelos atores do MRSB, desenvolve suas funções de forma paralela e competitiva ao sistema público, apresentando 
*Orcid (Open Researcher and Contributor ID). concepção de assistência que desrespeita os princípios expostos na máxima constitucional, incentivando à mercantilização e atribuindo valor de mercadoria às ações e serviços de saúde. Dessa forma, o SUS, com seu caráter universal e equitativo, desempenha papel importante na redução das desigualdades sociais.

Para ultrapassar o aspecto de reforma setorial e avançar no projeto de reforma de caráter geral, precisa-se resgatar algumas bandeiras, entre elas: 1) reforma tributária: que busca alterar o modelo regressivo de taxação de impostos, tributar heranças e grandes fortunas; 2) reforma política: que pretende reformular as regras da organização política brasileira, mudar o sistema e o financiamento eleitoral; 3) reforma agrária: que busca a redistribuição de terras e consequente melhoria nas condições de vida da população rural.

Ademais, deve-se lutar pelo fim dos subsídios concedidos às operadoras de planos de saúde, bem como fortalecer a regulação do Estado no setor suplementar, retomando os projetos de transformação social que foram almejados no MRSB. Este estudo avança na análise do processo histórico de 30 anos do SUS e apresenta de forma consolidada elementos-chave que precisam ser urgentemente resgatados para que o sistema público não seja desestruturado, tal como tem sido apresentado como situação incontornável rumo à privatização dos serviços públicos de saúde.

\section{Colaboradores}

Celuppi IC (0000-0002-2518-6644)* contribuiu para a concepção, o planejamento, a análise e a interpretação dos dados; revisão crítica do conteúdo; e aprovação da versão final do manuscrito. Geremia DS (0000-00032259-7429)* contribuiu para a concepção, o planejamento, a análise e a interpretação dos dados; revisão crítica do conteúdo; e aprovação da versão final do manuscrito. Ferreira J (0000-0002-8284-7883)* contribuiu para a revisão crítica do conteúdo e a aprovação da versão final. Pereira AMM (0000-0002-24979861)* contribuiu para a revisão crítica do conteúdo e a aprovação da versão final. Souza JB (0000-0002-0512-9765)* contribuiu para a revisão crítica do conteúdo e a aprovação da versão final.

\section{Referências}

1. Paim J, Travassos C, Almeida C, et al. The Brazilian health system: history, advances, and challenges. Lancet. 2011; 377(9779):1778-1797.

2. Geremia DS. Financiamento público de saúde: estudo de caso de um município da região metropolitana do Rio de Janeiro [dissertação] [internet]. Rio de Janeiro: Universidade do Estado do Rio de Janeiro; 2011.
3. Agência Nacional de Saúde Suplementar (ANS). Dados gerais. Brasília, DF; 2016.

4. Marques RM, Piola SF, Ocké-Reis CO. Desafios e perspectivas futuras no financiamento do SUS. In: Marques RM, Piola SF, Roa AC. Sistema de Saúde no Brasil: organização e financiamento. Rio de Janeiro: Ministério da Saúde; 2016, p. 247-258. 
5. Lefévre F, Lefévre AMC, Teixeira JJV. O discurso do sujeito coletivo: uma nova abordagem metodológica em pesquisa qualitativa. Caxias do Sul: Educs; 2000.

6. Lefévre F, Lefévre AMC. O discurso do sujeito coletivo: um novo enfoque em pesquisa qualitativa (desdobramentos). Caxias do Sul: Educs; 2003.

7. Pochmann M. A segunda globalização capitalista e o impasse nas políticas de bem-estar social. In: Rodrigues PHA, Santos IS. Políticas e riscos sociais no Brasil e na Europa: convergências e divergências. São Paulo: Hucitec; 2017.

8. Rizzotto MLF, Campos GWS. O Banco Mundial e o Sistema Único de Saúde brasileiro no início do século XXI. Saude soc. 2016; 25(2):263-276.

9. Mendes AN. A saúde pública brasileira no contexto da crise do Estado ou do capitalismo? Saude soc. 2015; 24(1):63-78.

10. Banco Mundial. Brazil: the new challenge of adult health. Washington, DC: Banco Mundial; 1991.

11. Banco Mundial. World Development Report 1993: Investing in Health. Washington, DC: Banco Mundial. Nova Iorque: Oxford University Press; 1993.

12. Banco Mundial. The organization, provision and financing of health at the Brazil: an schedule for the 90s. Washington, DC: Banco Mundial; 1995.

13. Filippon J, Giovanella L, Konder M, et al. A "liberalização” do Serviço Nacional de Saúde da Inglaterra: trajetória e riscos para o direito à saúde. Cad. Saúde Pública. 2016; 32(8):1-14.

14. Marques RM. O direito à saúde no mundo. In: Marques RM, Piola SF, Roa AC. Sistema de Saúde no Brasil: organização e financiamento. Rio de Janeiro: Ministério da Saúde; 2016.
15. Associação Brasileira de Saúde Coletiva. Febraplan e a disputa real pelo Sistema de Saúde Universal: considerações sobre a atuação recente do setor privado nas políticas saúde [internet]. [acesso em 2018 jun 22]. Disponível em: https://www.abrasco.org.br/ site/outras-noticias/sistemas-de-saude/febraplan-e-disputa-real-pelo-sistema-de-saude-universal-consideracoes-sobre-atuacao-recente-do-setor-privado-nas-politicas-saude/33855/.

16. Dain S. Os vários mundos do financiamento da Saúde no Brasil: uma tentativa de integração. Ciênc. Saúde Colet. 2007; 12(supl):1851-1864.

17. Geremia DS. Federalismo e gestão metropolitana para o planejamento territorial dos serviços de saúde [tese]. Rio de Janeiro: Universidade do Estado do Rio de Janeiro; 2015.

18. Morais HMM, Albuquerque MSV, Oliveira RS, et al. Organizações Sociais da Saúde: uma expressão fenomênica da privatização da saúde no Brasil. Cad. Saúde Pública. 2018; 34(1):1-13.

19. Santos NR. SUS, política de Estado: seu desenvolvimento instituído e instituinte e a busca de saídas. Ciênc. Saúde Colet. 2013 [acesso em 2019 jul 9]; 18(1):273-280. Disponível em: http://www.scielo.br/scielo.php?pid=S1413$-81232013000100028 \&$ script=sci_abstract $\&$ tlng=pt.

20. Paim JS. Sujeitos da antítese e os desafios da práxis da Reforma Sanitária Brasileira. Saúde debate. 2017; 41(3):255-264.

Recebido em 08/10/2018

Aprovado em 17/03/2019

Conflito de interesses: inexistente

Suporte financeiro: não houve 